\title{
Odor-Induced Variation in Anxiety-Like Behavior in Mice is Associated with Discrete and Differential Effects on Mesocorticolimbic Cholecystokinin mRNA Expression
}

\author{
Andrea L.O. Hebb, Ph.D., Robert M. Zacharko, Ph.D., Hélène Dominguez, D.E.A., \\ France Trudel, M.Sc., Sylvie Laforest, B.Sc., and Guy Drolet, Ph.D.
}

The present investigation assessed alterations in mesocorticolimbic cholecystokinin (CCK) mRNA following novel predator and non-predator odor exposure and lightdark testing in CD-1 mice. In brief, acute exposure of CD-1 mice to the predator odor, 2,5-dihydro-2, 4,5-

trimethylthiazoline (TMT; the major component of the anal gland secretions of the red fox), or the control odor, butyric acid (BA), suppressed rearing behavior during odor presentation, subsequently induced anxiety in the light dark test, and was associated with increased mesocorticolimbic $C C K m R N A$ relative to saline treated mice. Only mice exposed to TMT displayed elevated freezing behaviors during odor treatment. In the light-dark test, mice exposed to either BA or TMT took longer to reenter the light section of the apparatus and spent less cumulative time in the light relative to mice exposed to saline. The decreased time spent in the light as well as light dark transitions were exaggerated among mice exposed to fox odor. Odor presentation was associated with increased CCK $m R N A$ in mesocorticolimbic sites. Butyric acid was associated with enhanced CCK gene expression in the VTA, while both BA and TMT were associated with increased medial prefrontal cortex ( $m$ PFC) CCK mRNA levels. Increased CCK mRNA within the VTA and MPFC was evident among mice despite testing in the light-dark box. In contrast, basolateral nucleus of the amygdala (BLA) CCK mRNA was enhanced following odor exposure among mice in the light dark test relative only to saline treated mice which demonstrated a natural decrease in BLA CCK $m$ RNA following the light dark test. The differential pattern of CCK mRNA associated with discrete psychogenic stressor manipulations and the provocation of anxiety-like behavior associated with such experiences is discussed.

[Neuropsychopharmacology 27:744-755, 2002]

(C) 2002 American College of Neuropsychopharmacology.

Published by Elsevier Science Inc.
From the Institute of Neuroscience, Carleton University, Ottawa, Ontario, Canada (ALOH, RMZ), and CHUL Research Centre, Université Laval, Québec, Canada (HD, FT, SL, GD).

Address correspondence to: Dr. Guy Drolet, CHUL Research Centre, Neuroscience Unit, 2705 Laurier Blvd., Ste-Foy, Québec, Canada, G1V 4G2. Tel.: (418) 654-2152; Fax: (418) 654-2753; gdrolet @crchul.ulaval.ca

Received February 12, 2002; revised April 19, 2002; accepted April 24, 2002.

Online publication: $4 / 26 / 02$ at www.acnp.org/citations/ Npp042602295.
KEY WORDS: Fox odor; Fear; Basolateral nucleus of the amygdala; Ventral tegmental area; Medial prefrontal cortex

It is well documented that stressful life events contribute to the etiology of mood disorders (Post et al. 1998). A role for cholecystokinin (CCK) in the induction of anxiety in infrahuman subjects (Cohen et al. 1998), promotion of panic (Bradwejn et al. 1990), and co-expression of depression (Lofberg et al. 1998) in humans appears to be conspicuous. Several investigators have argued that some species-specific stressors may be rel- 
evant in animal models of affective disorders (Blanchard and Blanchard 1988). Indeed, in independent experiments, exposure of rodents to predator odor elicits neurochemical and behavioral perturbations which include increased anxiety-like behavior in the elevated plus maze (McGregor and Dielenberg 1999) and lightdark box (Adamec 2001) in rats, increased freezing in novel environments (Hotsenpiller and Williams 1997), increased risk assessment (Blanchard et al. 1998), decreased sucrose consumption (Calvo-Torrent et al. 1999) in mice and increased concentrations of CCK-4 in the rat olfactory bulb, mesocortex, nucleus accumbens, and central amygdaloid nucleus as well as increased CCK-8S concentrations in the striatum (Pavlasevic 1993) relative to neutral odors. In the present investigation we hypothesized that the presentation of predator odors would incite central mesocorticolimbic CCK variations underlying behaviors associated with fear (e.g. freezing) and mild anxiety states (e.g. light-dark test) in mice.

The present experiment assessed: (1) defensive behaviors exhibited during the presentation of novel odors (predator and non-predator) in the home cage; (2) anxiety-like behavior in the light dark test immediately following odor exposure in the home-cage; and (3) the expression of the CCK mRNA from the ventral tegmental area (VTA), medial prefrontal cortex (mPFC) and basolateral nucleus of the amygdala (BLA), among CD-1 mice following either the odor or the odor + light-dark test. The application of rodent predator odor substances extracted from the scent glands of the fox and the weasel favors quantitative evaluation of experience intensity while allowing comparison of nonpredatory odor intensity (see Lu et al. 1993; Zibrowski et al. 1998) other than neutral odors such as saline or clean shavings. For example, 2,5-dihydro-2, 4,5-trimethylthiazoline (TMT) and 2-propythietane are substances isolated from the fox (vulpes vulpes) (VernetMaury 1980) and weasel (mustela erminea) (Crump and Moors 1985) anal scent gland, respectively. It has previously been demonstrated that TMT suppressed open-field activity, enhanced freezing, elevated basolateral amygdaloid and mesocortical DA turnover and elevated corticosterone levels in rats relative to saline and the pungent, non-predator control substance, butyric acid (Morrow et al. 2000; VernetMaury 1980; Vernet-Maury et al. 1992; Wallace and Rosen 2000). The purpose of the present experiment was to address whether anxiety in the light-dark test as well as mesocorticolimbic CCK mRNA variations following odor exposure in mice was specific to the threat of an odor (TMT; predator odor) or merely due to the presentation of novel odors (butyric acid; control odor).

\section{MATERIALS AND METHODS}

\section{Subjects}

Forty-eight naive 3-month-old male, $C D-1$, mice $(n=48)$ (Charles River, St Constant, Quebec) were group housed (5 weeks of age) with ad libitum access to food and water and maintained on a $12 \mathrm{~h}$ light-dark schedule. Mice were approximately three months old at time of testing. Two to three weeks prior to behavioral testing, mice were individually housed and handled daily. Handling consisted of picking up animals gently by the tail and allowing free exploration of a gloved hand for $2 \mathrm{~min}$. All behavioral testing was conducted between 9 A.M. and 2 P.M. in laboratory quarters removed from the animal housing area. Our local University Animal Care Committee approved the experimental protocol in accordance with the guidelines detailed by the Canada Council on Animal Care.

\section{Odor}

Mice were exposed to either 2,5-dihydro-2, 4,5-trimethylthiazoline, the major component of the anal gland secretions of the red fox, purchased from Phero-Tech, (Delta, BC), to butyric acid (Sigma), a pungent, nonpredatory control odor, or to physiological saline, the odor-free control substance. All odorants were impregnated in sterile gauze $(5 \times 5 \mathrm{~cm})$ and placed in the home cage in 10-cm glass petri dishes covered by wire mesh. A Canon ES950 video camera mounted above the cage recorded the behavior of mice during odor presentation.

\section{Behavioral Testing}

Light-dark Test. The light-dark apparatus consisted of a rectangular Plexiglas box $(20 \times 47 \times 20 \mathrm{~cm})$ with the dark section comprising one third and the light section comprising the remaining two thirds of the chamber. The two sections of the apparatus were separated by a Plexiglas partition with an opening $(12.5 \times 5 \mathrm{~cm})$ allowing passage from the open "light" section to the enclosed "dark" portion of the chamber. A 40W light bulb, positioned $10 \mathrm{~cm}$ above the center of the light compartment, provided illumination, while red, translucent Plexiglas served as a roof of the dark chamber.

Procedure. Mice were initially habituated to placement beneath the video camera with the glass petri dish placed in their home cage but no odors present for 10 min on three consecutive days. On each habituation trial, the wire cage top was removed and replaced with a clear Plexiglas sheet to enable observation of risk assessment behaviors. Mice were transported to another testing area where the light-dark test would be performed. Mice were not exposed to the light-dark test during the habituation procedure. Mice were gently re- 
trieved from the home-cage and handled briefly (2 min). Each animal was immediately returned to the home cage and transported back to main animal housing unit.

Following habituation procedures, mice were randomly assigned to predator $(n=16)$, butyric acid $(n=16)$, or saline treatment conditions $(n=16)$. Based on previously established criteria employed in ensuring equal odor potency of these compounds as presented to each subject, $35 \mu \mathrm{l}$ of predator odor, $105 \mu \mathrm{l}$ butyric acid, or $105 \mu \mathrm{l}$ sterile saline was applied to sterile gauze, which would approximately supply the same number of molecules in the air, as previously measured by charcoal absorption (Hotsenpiller and Williams 1997). The gauze was placed in the cage for $10 \mathrm{~min}$. Twenty-four mice were then transported immediately $(5 \mathrm{~min})$ to the second experimental room where activity in the light-dark test was recorded ( $\mathrm{n}=8$ for each of the three odor groups). Each subject was placed in the center of the light compartment facing the dark chamber entry. The latency for the mouse to enter the dark chamber, the latency for the mouse to renter the light chamber following initial dark chamber escape, transition frequency between the light and dark compartments as well as cumulative light and dark compartment occupancy were recorded over two consecutive 5-min sessions. A subject was considered to have entered a compartment when all four paws were positioned within that compartment. A Samsung SCX954 video camera, positioned above the light-dark box, recorded the behavior of the mice. The remaining 24 mice did not experience the light-dark test and served as controls for apparatus exposure. Five animals from each odor and light-dark test group $(n=30)$ were perfused intracardially with $4 \%$ paraformaldehyde (3.8\% Sodium Borate) and brains removed for CCK mRNA in situ hybridization.

In situ Hybridization: CCK mRNA. A specific cDNA probe was obtained by DNA amplification starting from rat cerebral cortex RNA. Total RNA was isolated from rat brain using the guanidine isothyocianate method (Chomezinski and Sacchi 1987). Briefly, brain tissue was homogenized at $4^{\circ} \mathrm{C}$ in a buffer containing 50 $\mathrm{mM}$ Tris-HCI (pH 7.5), $4 \mathrm{M}$ guanidine isothiocyanate, $10 \mathrm{mM}$ EDTA, N-laurylsarcosine (1\% wt/vol), and 2-mercaptoethanol ( $1 \% \mathrm{vol} / \mathrm{vol})$. The samples were extracted twice with phenol/chloroform $(1: 1 \mathrm{vol} / \mathrm{vol})$ and the nucleic acids were recovered by precipitation with ethanol. DNAse treatment of the nucleic acids was followed by a further extraction with phenol/chloroform $(1: 1 \mathrm{vol} / \mathrm{vol})$ and RNA concentration was determined spectrophotometrically by measuring the absorbance at 260 nanometers. For direct DNA amplification, $1 \mu \mathrm{g}$ of cortex RNA was used. Reaction was performed using a Titan One tube RT-PCR system (Roche) and primers at $400 \mu \mathrm{m}$ each in a $50 \mu \mathrm{l}$ reaction tube. The parameters for
DNA amplification were $30 \mathrm{~min}$ at $42^{\circ} \mathrm{C}$ for reverse transcriptase, $94^{\circ} \mathrm{C}$ for $2 \mathrm{~min}$, annealing temperatures at $55^{\circ} \mathrm{C}$ for $30 \mathrm{~s}$, where the annealing temperature was optimized for both primers and elongation at $68^{\circ} \mathrm{C}$ for 7 $\mathrm{min}$. The sense primer 1 was $5^{\prime}$ CCG-CCT-GCC-CTCAAC-TTA $3^{\prime}$ position $40-58$ and primer 2 was $5^{\prime}$ AAACAT-TGC-CTT-CCC-ACC 3' position 644-626. DNA amplification products were analyzed by gel electrophoresis on an agarose gel $(0.8 \% \mathrm{wt} / \mathrm{v})$, which was stained with ethidium bromide. To subclone amplified DNA, the polymerase chain reaction (PCR) product was purified and ligated (T4 DNA ligase) to SMA1 (blunt) digested $\mathrm{p}$ Blue script SK $( \pm)$ vector (Promega). To produce the anti-sense probe, DNA was digested with EcoR1 and T3 polymerase. To produce the sense probe, DNA was digested with Sac1 and T7 polymerase. Hybridization with the sense probe did not reveal any positive signal in mouse brain.

\section{Data Analysis}

Odor Presentation. The frequency of contacts with the odorant cloth, digging, defensive burying, freezing, rearing, stretch attend postures, and grooming, as well as the duration of contact with the odorant cloth, digging, defensive burying, and freezing behaviors among mice during odor exposure in the home-cage were scored. Briefly, complete cessation of movement except respiratory muscles (freezing), orientation toward the odorant cloth with the top of the back lower than the ears (stretched attention), moving toward the odorant cloth while pushing or spraying bedding material toward it (defensive burying) or physical contact with the cloth (cloth contacts) were included as risk assessment behaviors of mice during odor presentation. Three nonagonistic behaviors (digging, rearing, grooming) were also scored in response to the odorant treatments among CD-1 mice in the home-cage by an experimenter blind to the experimental condition of each animal. All behavioral scores were analyzed by 1-way analyses of variance for independent groups on data obtained following stressor treatment. Fisher's least significant difference (LSD) multiple comparisons were employed where appropriate and the .05 level of significance was adopted for all comparisons.

Light-dark Test. Behavioral scores describing dark compartment latency, light chamber reentry, time in light during the initial and subsequent 5-min trial block as well as cumulative time in light and transitions between the light and dark compartments were analyzed by a 1-way analysis of variance for independent groups on data obtained following stressor encounter. Fisher's Least Significant Difference (LSD) multiple comparisons were employed where appropriate and the .05 level of significance was adopted for all comparisons. 
Quantitative Analysis of CCK mRNA. Nuclei were identified using the mouse brain atlas of Paxinos and Franklin (1997). For each mouse, amygdaloid sections corresponding to level 43-44, the medial prefrontal cortex corresponding to levels 14-19, and the VTA corresponding to levels 58-62 were examined. Blind quantitative analysis of hybridization signal for CCK mRNA was performed on Kodak X-ray film. The signal was analyzed with NIH image software. Densitometric analyses, yielding measures of optical density, area of signal and integrated optical (i.e., area of the signal $\times$ average optical density) were performed according to a standard scale established using ${ }^{14} \mathrm{C}$ standard slides.

The density of the respectively identified cell types (i.e., positively stained cells) were evaluated in the basolateral amygdaloid nucleus (BLA), ventral tegmental area (VTA), and mesocortex (mPFC) and were subjected independently to ANOVA as a 3 (Saline, Butyric Acid, Predator) $\times 2$ (Light-Dark Box, No Light-Dark Box) design. Fisher's Least Significant Difference (LSD) multiple comparisons were employed where appropriate and the .05 level of significance was adopted for all comparisons.

\section{RESULTS}

\section{Home Cage Exposure}

Analysis of variance of the number of contacts with the odorant cloth $\left(\mathrm{F}_{2,45}=42.47, p<.001\right)$, freezing behavior frequency $\left(\mathrm{F}_{2,45}=21.89, p<.001\right)$, frequency of defensive burying behaviors $\left(\mathrm{F}_{2,45}=15.12, p<.001\right)$, stretch attend frequency $\left(\mathrm{F}_{2,45}=9.30, \mathrm{p} .<.001\right)$ and number of rears $\left(\mathrm{F}_{2,45}=11.93, p>.001\right)$ among mice during odor presentation in the home cage revealed a significant main effect of odor (see Figure 1). Mice exposed to butyric acid or predator odor contacted the odorant cloth less than mice exposed to saline while mice exposed to fox odor made significantly fewer contacts with the odorant cloth than mice exposed to either saline or butyric acid. Mice exposed to fox odor displayed significantly elevated instances of freezing relative to mice exposed to either saline or butyric acid, while there were no significant difference in the frequency of freezing behavior among mice exposed to saline or butyric acid. Mice exposed to butyric acid or predator odor displayed significantly elevated instances of defensive burying relative to mice exposed to saline, while mice exposed to fox odor displayed significantly more incidents of defensive burying activity relative to mice exposed to saline or butyric acid. Finally, mice exposed to butyric acid or predator odor displayed a significant increase in the frequency of stretch attend behaviors in comparison to mice which were exposed to saline. There was no significant difference in stretch attend frequency among mice exposed to fox or butyric acid (see
Figure 1, panel A). Mice exposed to butyric acid or predator odor displayed decreased rearing behavior in comparison with mice exposed to saline. Mice exposed to predator odor during home-cage odor exposure displayed reduced rearing relative to mice exposed to butyric acid (see Figure 1, panel B). There was no effect of odor presentation on digging $\left(\mathrm{F}_{2,45}=1.762, p>.05\right)$ or

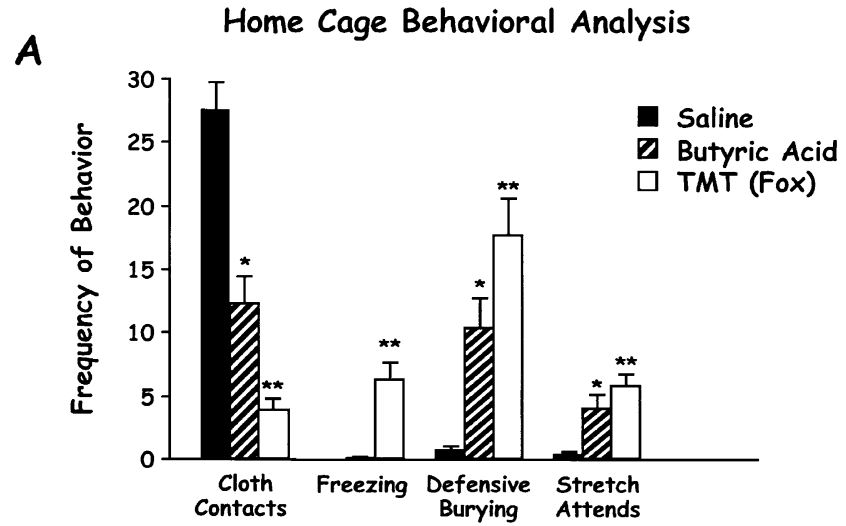

B
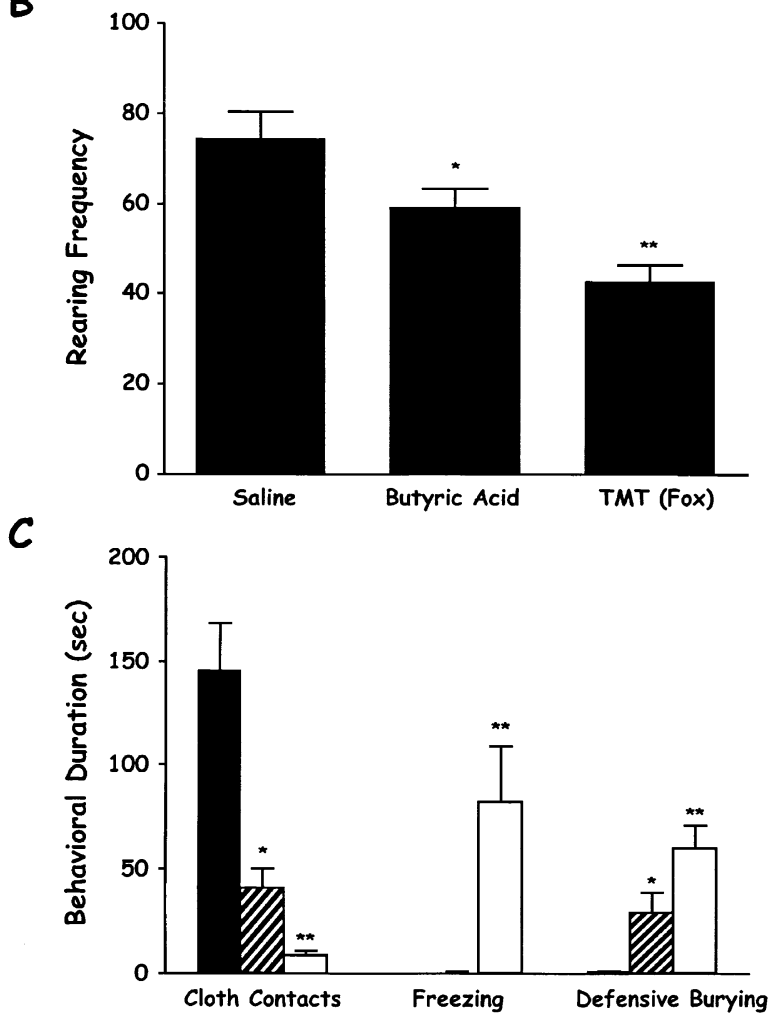

Figure 1. Home cage behavioral frequency (A), rearing frequency (B) and duration of home-cage defensive behaviors (C) exhibited among mice during a 10 min saline, butyric acid or fox odor (TMT) presentation. These results represent means \pm SEM of 16 mice per group. *A statistically significant difference $(p<.05)$ of butyric acid or TMT odor treatment relative to saline treated mice. ${ }^{* *} \mathrm{~A}$ statistically significant difference $(p<$ .05) between butyric acid and TMT odor treatments for a particular home-cage behavior observed during odor presentation. 
grooming $\left(\mathrm{F}_{2,45}=1.95, p>.05\right)$ behavior of mice during odor presentation.

Analysis of variance of the duration of: (1) contact with the odorant cloth $\left(\mathrm{F}_{2,45}=24.72, p<.001\right)$; (2) freezing $\left(\mathrm{F}_{2,45}=9.45, p<.001\right)$; and (3) defensive burying $\left(\mathrm{F}_{2,45}=12.53, p<.001\right)$ among mice during odor presentation in the home cage revealed a main effect of odor. Mice exposed to butyric acid or predator odor displayed decreased duration of contact with the odorant cloth relative to mice exposed to saline while mice exposed to fox odor displayed decreased duration of contact with the odorant cloth relative to mice exposed to butyric acid. Mice exposed to fox odor displayed a longer duration of freezing relative to mice exposed to saline or butyric acid. There was no significant difference in the duration of freezing behavior among mice exposed to saline or butyric acid. Finally, mice exposed to butyric acid or predator odor displayed a significantly increased duration of defensive burying relative to mice exposed to saline. Mice exposed to fox odor displayed a longer duration of defensive burying relative to mice exposed to butyric acid (see Figure 1, panel C). There was no effect of odor presentation on duration of digging $\left(\mathrm{F}_{2,45}=0.329, p>.05\right)$ of mice during odor presentation.

Light-Dark Test. Analysis of variance of dark chamber escape latency among mice immediately following odor exposure failed to reveal a significant effect of odor $\left(\mathrm{F}_{2,21}=1.58, p>.05\right)$. However, analysis of variance of light chamber reentry latency among mice immediately following odor exposure revealed a significant effect of odor $\left(\mathrm{F}_{2,21}=3.87, p<.05\right)$. Mice exposed to either butyric acid or predator odor took longer to reenter the light section of the apparatus relative to mice exposed to saline. There were no differences in reentry latency among mice treated with predator odor or butyric acid (see Figure 2).

Analysis of variance of the cumulative time spent in the light chamber of the light dark box among mice immediately following odor exposure revealed a significant effect of odor $\left(\mathrm{F}_{2,21}=7.63, p<.01\right)$. Mice exposed to either butyric acid or predator odor spent less time in the light section of the apparatus relative to mice exposed to saline. There were no differences in the amount of cumulative time spent in the light among mice exposed to butyric acid or TMT. Analysis of variance of the time spent in the light during the first and second 5-min intervals among mice immediately following odor exposure revealed a main effect of odor $\left(\mathrm{F}_{2,21}=6.57, p<.01\right.$ and $\mathrm{F}_{2,21}=6.80, p<.01$, respectively). During the first 5 -min segment of light dark box exposure, mice exposed to either butyric acid or predator odor spent less time in the light section of the apparatus relative to mice exposed to saline. During the second 5-min segment of light dark box exposure, mice exposed to either butyric acid or predator odor spent less time in the light section

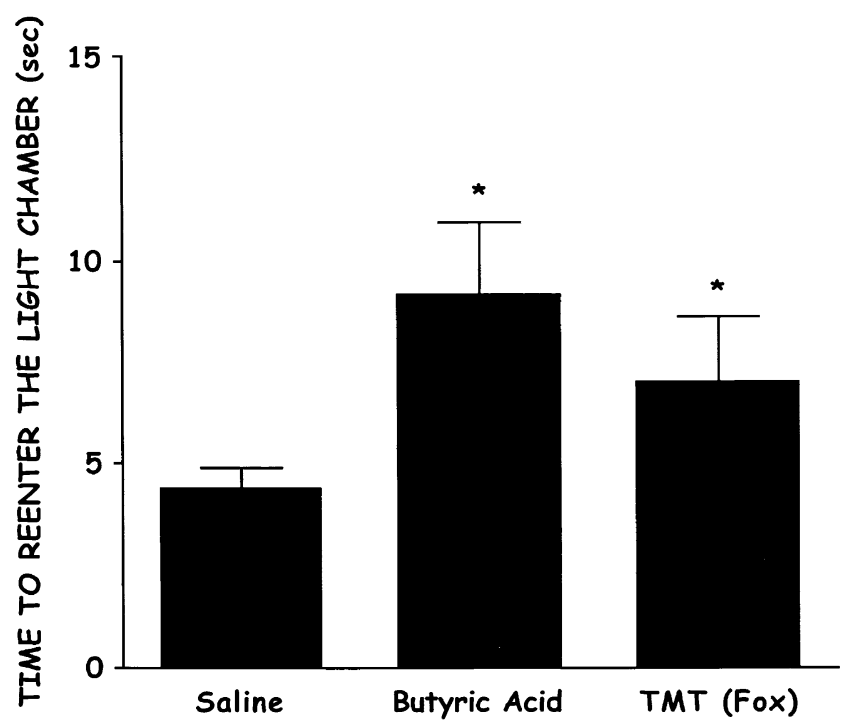

Figure 2. Light chamber reentry latency of mice following initial dark compartment escape immediately following a 10-min saline, butyric acid or fox odor (TMT) presentation. These results represent means \pm SEM of 8 mice per group. *A statistically significant difference $(p<.05)$ of butyric acid or TMT odor treatment relative to saline treatment.

of the apparatus relative to mice exposed to saline. Mice exposed to predator odor also spent less time in the lit portion of the apparatus relative to mice exposed to either saline or butyric acid (see Figure 3).

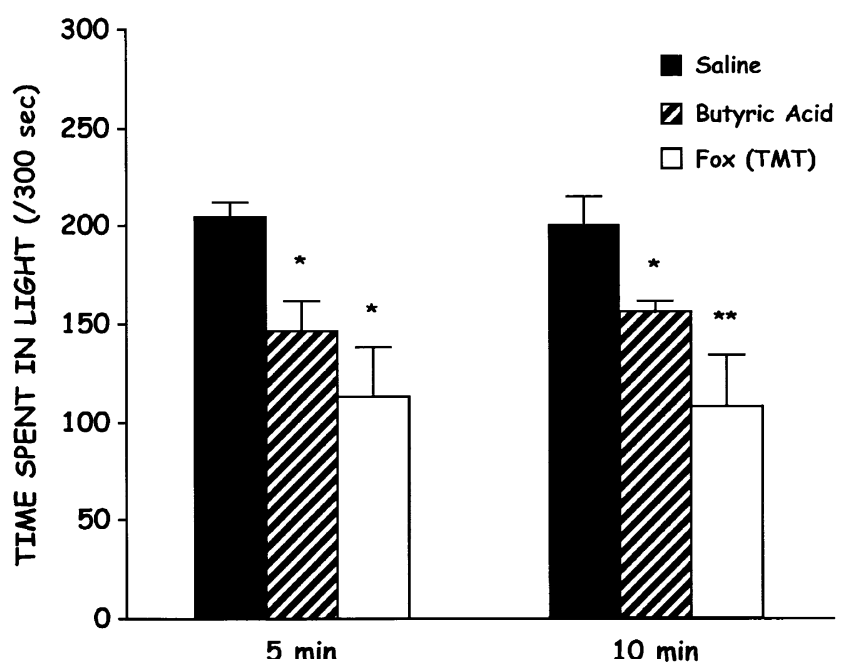

Figure 3. Mean time in light portion of the light dark box during the first and second consecutive 5-min intervals among mice following a 10 min saline, butyric acid or fox odor (TMT) presentation. These results represent means \pm SEM of 8 mice per group. *A statistically significant difference $(p<.05)$ of butyric acid or TMT odor treatment relative to saline treatment. **A statistically significant difference $(p<.05)$ of butyric acid and TMT odor treatments at the identical post-stressor interval. 
Analysis of variance of cumulative light and dark compartment transitions of mice revealed a significant effect of odor $\left(\mathrm{F}_{2,21}=3.66, p<.05\right)$. Mice exposed to predator odor displayed decreased light and dark compartment transitions relative to mice exposed to butyric acid or saline. There were no differences in cumulative transitions among mice treated with saline or butyric acid (see Figure 4).

\section{Quantitative Analysis of CCK mRNA}

Basolateral Amygdala (BLA). Analysis of variance of the optical density of CCK mRNA from the BLA among mice following odor presentation and light-dark box testing revealed an Odor X Light-dark box interaction $\left(\mathrm{F}_{2,20}=3.618, p<.05\right)$. Exposure to the light-dark box was associated with enhanced CCK mRNA levels among mice previously exposed to butyric acid or predator odor relative to saline treated mice which demonstrated a decrease in CCK mRNA following the light dark test. There were no differences in CCK mRNA levels among odorant conditions in the No Light-Dark Box treatment condition (see Figure 5).

Medial Prefrontal Cortex (mPFC). Analysis of variance of the optical density of CCK mRNA from the $\mathrm{mPFC}$ among mice following odor presentation and light-dark box testing revealed a main effect of odor $\left(\mathrm{F}_{2,19}=6.269, p<.01\right)$ and a main effect of light-dark box exposure $\left(\mathrm{F}_{1,19}=4.456, p<.05\right)$. Mice exposed to butyric acid or predator odor displayed elevated CCK mRNA relative to saline treated mice. Mice exposed to the light-dark box exhibited decreased CCK mRNA in the

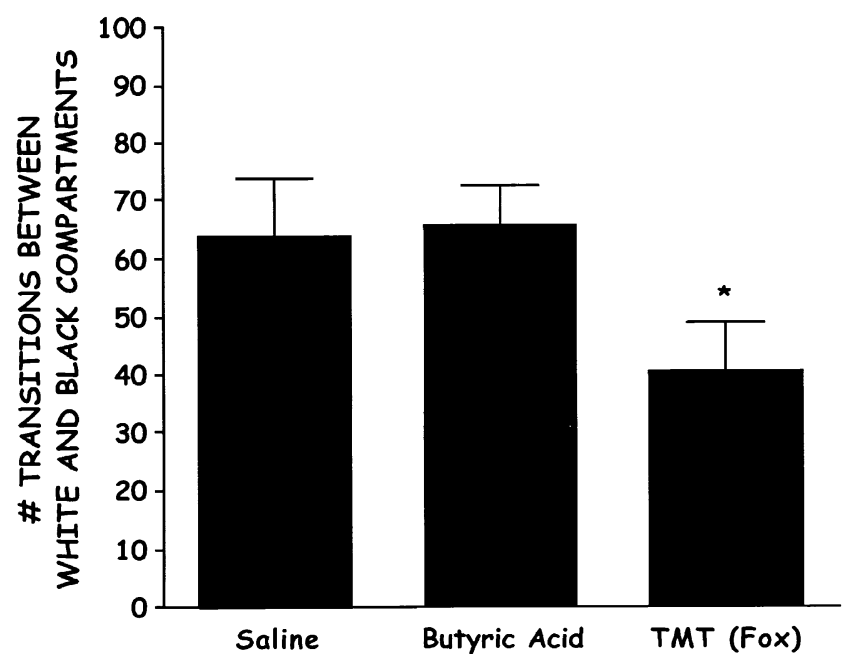

Figure 4. Cumulative light and dark compartment transitions of mice immediately following a 10-min saline, butyric acid or fox odor (TMT) presentation. These results represent means \pm SEM of 8 mice per group. ${ }^{*}$ A statistically significant difference $(p<.05)$ of butyric acid or TMT odor treatment relative to saline treatment.
mPFC relative to mice not tested in the light-dark box (see Figure 6).

Ventral Tegmental Area. Analysis of variance of the integrated density of CCK mRNA from the VTA among mice following odor presentation and light-dark box testing revealed a main effect of odor $\left(\mathrm{F}_{2,20}=4.442, p<.05\right)$. CCK mRNA was increased in mice exposed to butyric acid relative to saline or predator odor treated mice (see Figure 7).

\section{DISCUSSION}

The present study revealed that exposure of CD-1 mice to butyric acid or TMT in the home-cage induced risk assessment behavior during odor presentation and subsequent anxiety in the light-dark box relative to mice exposed to saline. In particular, discrete mesocorticolimbic CCK alterations were associated with both butyric acid and TMT relatively independent of anxiety in the light-dark test. While a 10-min exposure of CD-1 mice to butyric acid was associated with enhanced CCK mRNA in the VTA irrespective of light-dark box activity, both butyric acid and TMT exposure was associated with increased CCK mRNA in the mPFC. In the BLA, previous odor exposure prevented the natural decrease in CCK mRNA associated with light-dark testing observed in saline animals. It is likely that novel nonpredator and predator odors, promote increased expression of CCK mRNA in the VTA and the mesocortex or the mesocortex, respectively, with concomitant decreases in exploratory tendencies while increased CCK gene expression in the BLA are associated with alterations in motivation and anxiety.

\section{Behavioral Pattern of Defensive Behaviors Exhibited During Odor Exposure}

The behavioral pattern of defensive behaviors and rearing following TMT, butyric acid, or saline in the present investigation are consistent with previous investigations suggesting that a wide range of predator and nonpredator odors elevate risk assessment and decrease investigatory behaviors relative to neutral odor application during initial odor presentation (Blanchard et al. 1990; Garbe et al. 1993; Kemble and Bolwahnn 1997). Mice exposed to butyric acid or the synthetic predator odor, TMT, contacted the odorant cloth less, displayed increased frequency of stretch attends, decreased rearing behavior, and displayed enhanced defensive burying relative to mice exposed to saline. These data are consistent with previous investigations examining the behavioral profiles of mice in response to cat odor. In these studies, although mice display increased risk assessment behaviors to predator odor they exhibit simi- 


\section{Basolateral amygdala CCK mRNA}
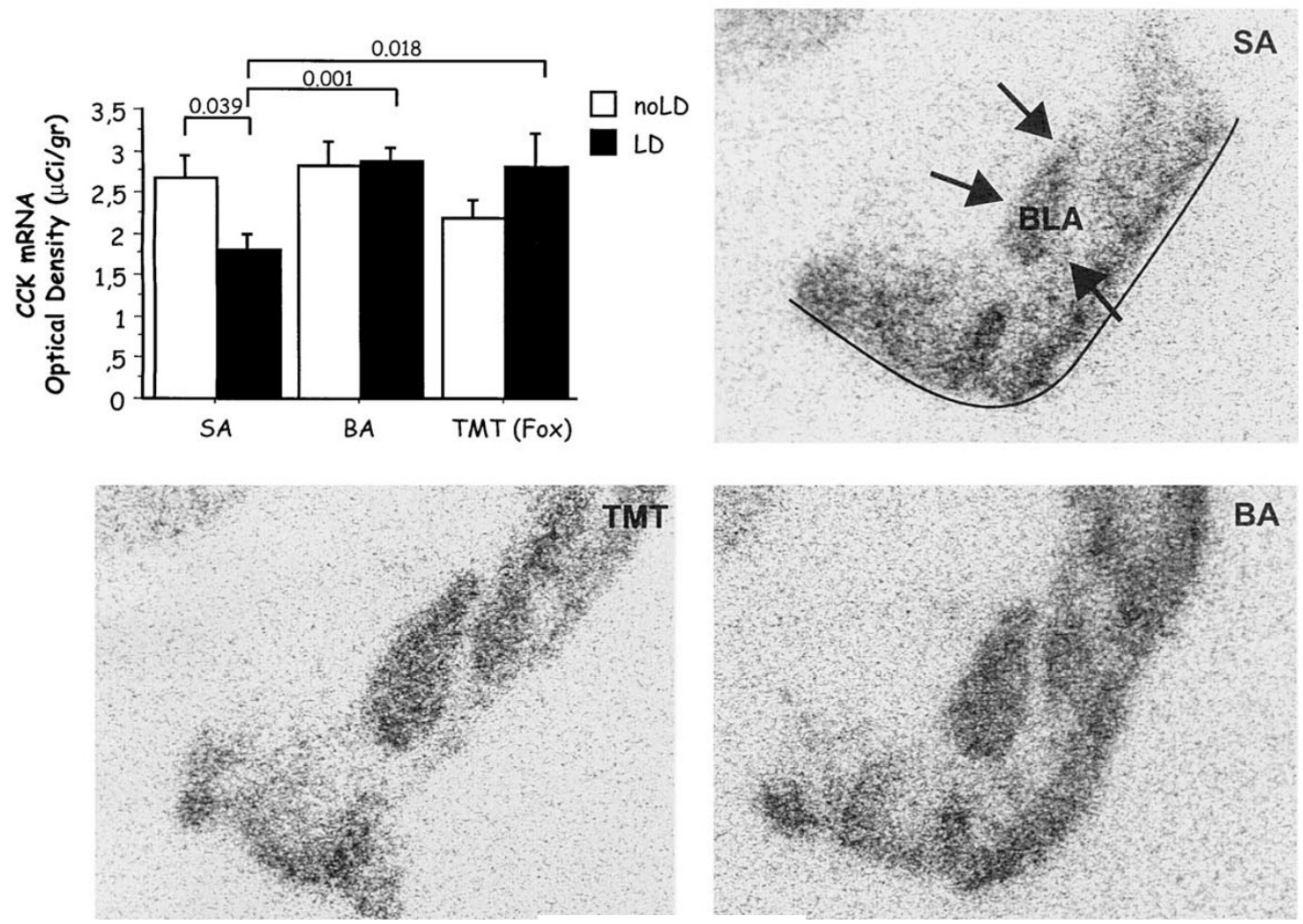

Figure 5. Cell mean and representative photomicrographs for optical density ( $\mu \mathrm{Ci}$ /gr) of basolateral nucleus of the amygdala (BLA) CCK mRNA following a 10 min saline (SA), butyric acid (BA) or fox odor (TMT) presentation among mice in light-dark and no light-dark testing schedules. These results represent means \pm SEM of 4 to 5 mice per group. The arrows are surronding the region of interest.

lar reactions to almost every other novel odor encountered (Blanchard et al. 1990; Kemble 1994; Kemble and Bolwahnn 1997). The stretched attend posture, as well as defensive burying, can be observed in rats in response to an object that incites both fear and curiosity, including electric prods, non-predator and predator odors, and are responsive to benzodiazepine administration (Blanchard et al. 1990; Molewijk et al. 1995). It should be noted that defensive burying of electric prods increases with increased shock intensity (Blanchard et al. 1990). Moreover, Wallace and Rosen (2000) report that TMT dose dependently increased freezing in rats. In effect, the presentation of novel non-predator and predator odors may induce a fear gradient that underlies the emergence and intensity of defensive behaviors among CD-1 mice. Indeed, in the present experiment, TMT was more effective than butyric acid in eliciting defensive behaviors during the respective odor presentation among CD-1 mice as revealed by depressed fre- quency and duration of cloth contact as well as elevated frequency and duration of freezing and defensive burying during odor presentation in the home-cage relative to mice exposed to butyric acid.

\section{Anxiety-like Behavior in the Light-Dark Test Following Odor Exposure}

Exposure of CD-1 mice to either butyric acid or TMT induced anxiety in the light-dark test relative to saline treated mice. Mice exposed to either butyric acid or TMT took longer to reenter the light section of the apparatus relative to mice exposed to saline. Mice exposed to either butyric acid or TMT also spent less time in the light section of the apparatus relative to mice exposed to saline. These data reflecting the effects of butyric acid and TMT in the light-dark test are consistent with the previous observation that time in light is more sensitive to the anxiogenic influence of stressor imposition rela- 


\section{Medial Prefrontal Cortex CCK MRNA}

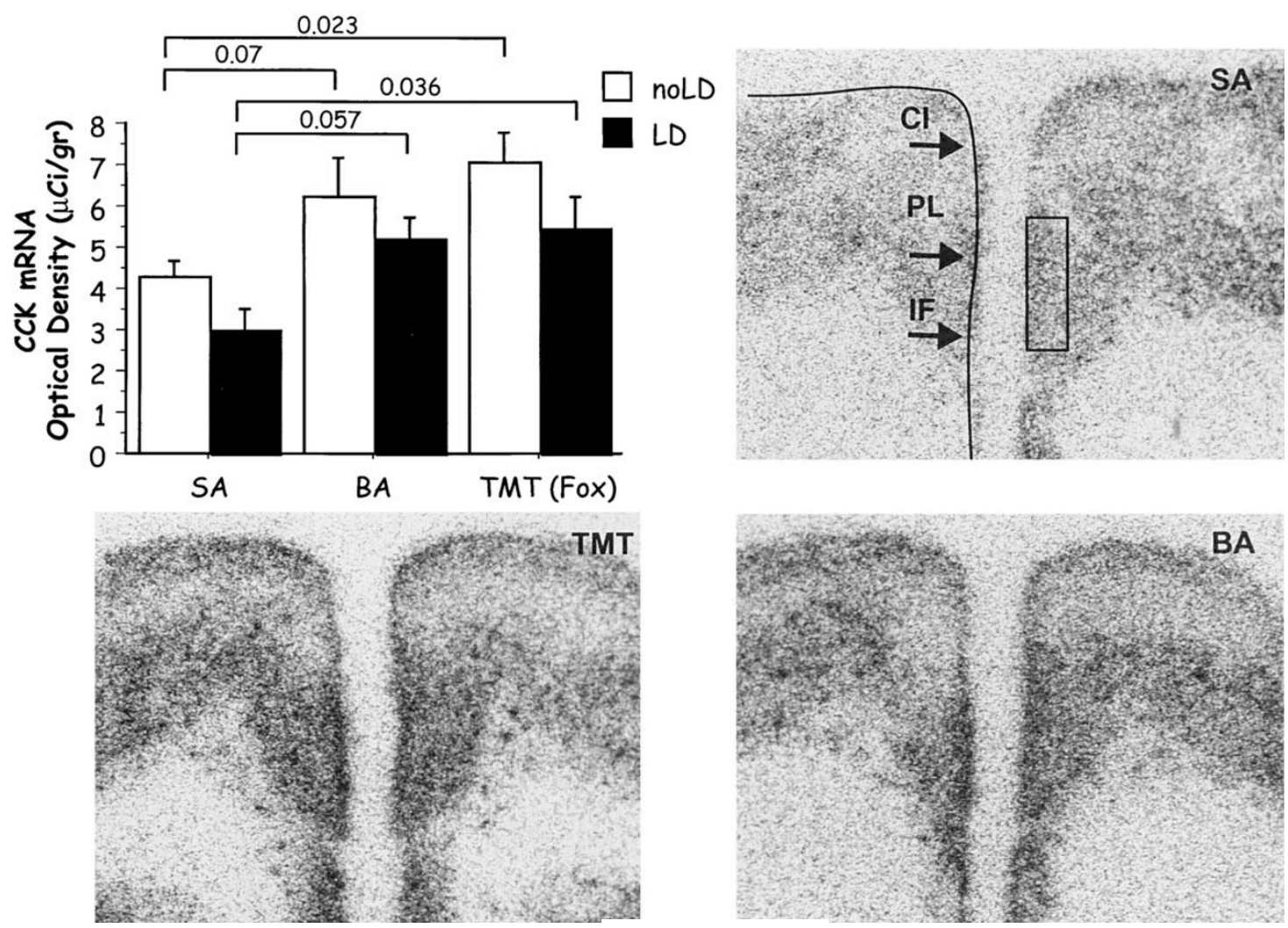

Figure 6. Cell mean and representative photomicrographs for optical density ( $\mu \mathrm{Ci} / \mathrm{gr})$ of medial prefrontal cortex (mPFC) CCK mRNA among mice following a 10 min saline (SA), butyric acid (BA) or fox odor (TMT) presentation and among mice in light-dark and no light-dark testing schedules. These results represent means \pm SEM of 3 to 5 mice per group. The rectangle encloses a representative sample area. CI; cingular cortex, PL; prelimbic cortex, IL; infralimbic cortex.

tive to transition scores (Kilfoil et al. 1989; MacNeil et al. 1997). Moreover, the presentation of odors (i.e., pungent versus non-pungent) is sufficient to induce anxiety in the light-dark test. In previous investigations, Hogg and File (1994) classified rats as responders or nonresponders to cat odor based upon the time sheltering during cat odor exposure. Both cat odor responders and non-responders displayed anxiety in the elevated plus maze. In comparison, our results revealed that exposure of mice to TMT produced a profile of anxiogenic effects that was paralleled in both transition scores and cumulative time in light. Mice exposed to TMT displayed decreased light and dark compartment transitions relative to mice exposed to butyric acid or saline. The decrease in transition frequency is an index of reduced exploration (Crawley and Goodwin 1980). Indeed, exposure of rats and mice to predators (Adamec 2001) and predator odors (Berton et al. 1998) decrease exploration in novel environments. Mice exposed to TMT spent less time in the lit portion of the apparatus relative to mice exposed to either saline or butyric acid. The exaggerated behavioral effect of TMT on time spent in the light was delayed and did not emerge until the second concurrent 5 -min test session. The emergence of exaggerated levels of anxiety in mice exposed to TMT suggests a gradual divergence of novel non-predator and species-relevant fear-evoking stimuli in inciting behavioral change.

\section{Mesocorticolimbic CCK mRNA Expression Following Odor Exposure and Light Dark Testing}

In the present investigation, CCK mRNA was increased from the mesocortex following exposure of mice to butyric acid $(57 \%)$ or predator odor $(73 \%)$ relative to saline exposure. Unexpectedly, exposure of CD-1 mice to the 


\section{Ventral Tegmental Area CCK MRNA}
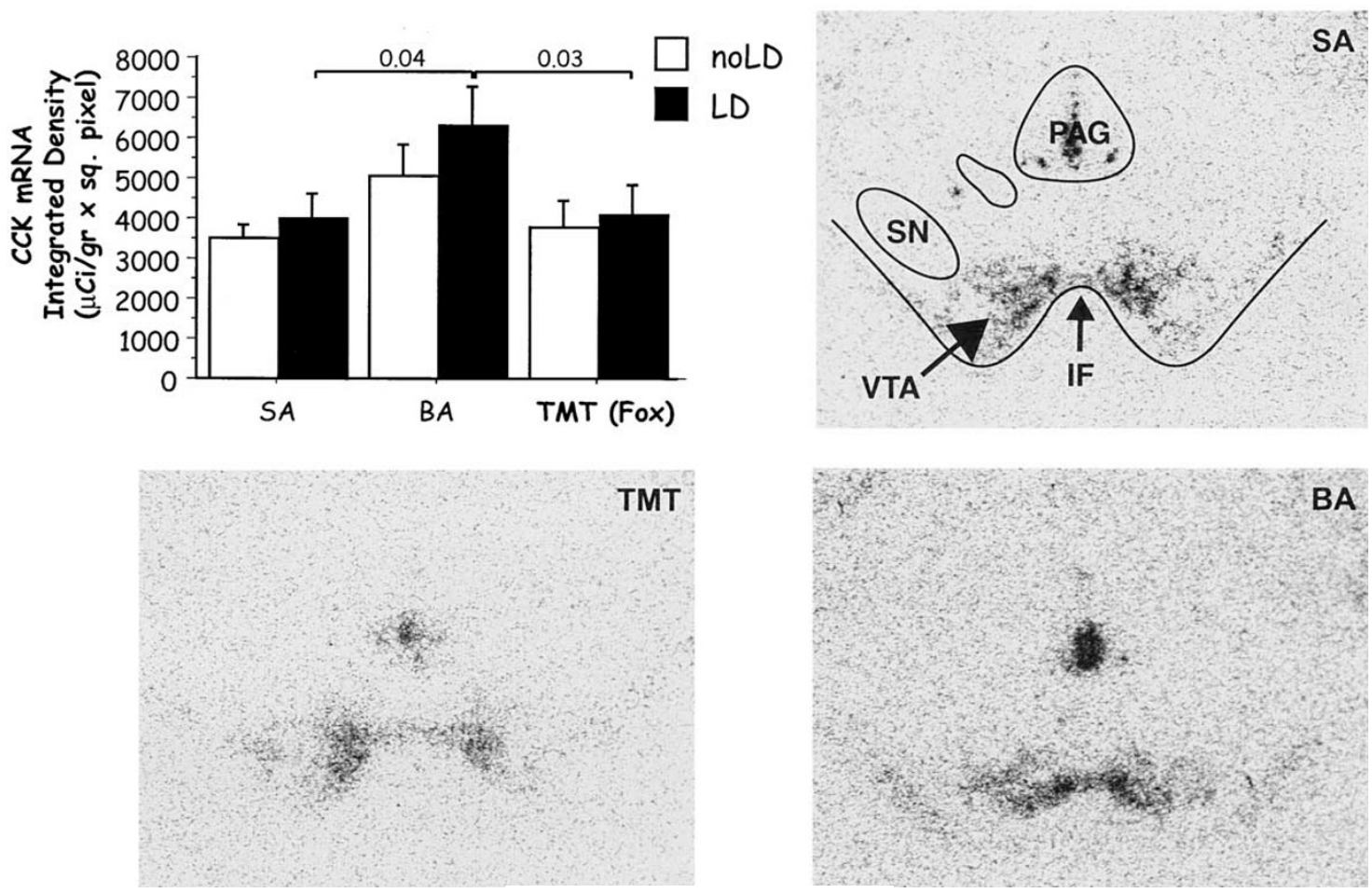

Figure 7. Cell mean and representative photomicrographs for integrated density $\left(\mu \mathrm{Ci} / \mathrm{gr} \times\right.$ sq. pixel $\left.10^{3}\right)$ of ventral tegmental area (VTA) CCK mRNA following a 10 min saline (SA), butyric acid (BA) or fox odor (TMT) presentation among mice in lightdark and no light-dark testing schedules. These results represent means \pm SEM of 3 to 5 mice per group. IF; interfascicular nucleus, PAG; periaqueductal gray, SN; substantia nigra.

light-dark box reduced CCK mRNA values relative to mice not exposed to the apparatus irrespective of odor treatment. In other investigations, rat cerebral cortex CCK mRNA levels were increased after a single injection of the anxiolytic agent diazepam (Rattray et al. 1993). In contrast, CCK mRNA was elevated in the VTA of mice exposed to butyric acid but not following TMT exposure relative to saline treated mice. Curiously, butyric acid failed to induce freezing behavior relative to saline or TMT treated mice yet was associated with increased CCK mRNA in the VTA and MPFC. Moreover, the increase in VTA and mPFC CCK mRNA among mice exposed to butyric acid or TMT was not associated with anxiety in the light-dark test. It should be underscored that while exposure of mice to butyric acid failed to incite freezing in response to odor presentation, defensive burying and stretch attends were increased relative to saline treated mice. Morrow et al. (2000) previously demonstrated that while a 20 min exposure of rats to either butyric acid or TMT increased corticosterone levels relative to saline exposure, only exposure of rats to
TMT increased DA turnover in the mPFC and basolateral amygdala relative to butyric acid and saline exposure. It has been suggested that mesencephalic CCK plays an important role in maintaining the responsiveness of DA neurons to afferent input and behaviorally relevant stimuli (Hamilton and Freeman 1995). Moreover, exposure to novel stimuli evoked investigatory activity and increased mesoaccumbens dopamine (DA) in rats. The phasic elevations in nucleus accumbens DA evoked by exposure to unconditioned novel stimuli were dependent on glutamate transmission in the VTA (Hooks and Kalivas 1995; Legault and Wise 2001; Vos et al. 1999).

Consistent with the demonstration that exposure of CD-1 mice to butyric acid or TMT induces anxiety in the light-dark test as indicated by reduced cumulative time in light and longer light reenter latency, mice exposed to these odors displayed increased CCK mRNA in the basolateral nucleus (BLA) of the amygdala. It should be underscored that the increase in BLA CCK mRNA was evident only among those mice tested in the light-dark box following respective odor treatment. 
The difference lay in a net decrease in CCK among saline mice relative to odor and light-dark test animals. Hence, previous odor exposure prevents the normal decrease in BLA CCK mRNA associated with the subsequent light-dark test. Taken together, these data suggest that odor presentation and not anxiety, per se, is associated with enhanced CCK mRNA in the mPFC and VTA while odor and light-dark box testing, irrespective of odor imposition, is associated with sustained BLA CCK mRNA.

The basolateral amygdaloid nucleus participates in fear conditioning in human (Furmark et al. 1997) and infrahuman (Davis 1992; Gewirtz et al. 1997; Graeff et al. 1993) subjects and may well assign motivational and emotional significance to stimuli previously paired with stressors (Davis and Shi 1999; Morgan and LeDoux 1995). In rats, lidocaine associated inactivation or electrolytic lesions of the basolateral nucleus of the amygdala prevented consolidation of the emotional learning and conditioning of acoustic startle (Gewirtz et al. 1998) as well as anxiety associated with repeated plus maze exposures (File et al. 1998). In humans (Davidson and Irwin 1999) and animals (Granon et al. 2000; Jinks and McGregor 1997; Morgan and LeDoux 1995), the amygdala and mesocortex appear to participate in the acquisition and retention of emotionally laden stimuli. The BLA plays a significant role in affective behavior that is thought to be regulated by DA afferents from the mPFC. For example, Rosenkranz and Grace (2001) demonstrated that the mPFC attenuates BLA neuronal activity via recruitment of BLA interneurons. Acute exposure of rats to TMT in an open field prompted increased DA metabolism, as measured by DOPAC/DA ratio, in the mPFC and BLA and increased serum corticosterone. No significant effect of TMT was noted in the core and shell of the nucleus accumbens or the striatum (Morrow et al. 2000). It should be noted that gentle handling also increased in vivo DA release from the basolateral aspects of the amygdala. Interestingly, such amygdaloid DA release was only evident during mild stressor application (Lanca et al. 1998).

In conclusion, the data of the present investigation reveal that enhanced CCK mRNA within the mesolimbic system, the basolateral nucleus of the amygdala in particular, following odor presentation is associated with anxiety in the light-dark test. Indeed, one of the mechanisms associated with the expression of anxiety incorporates an amygdaloid DA/CCK neurochemical mosaic which may encode the saliency of the environmental experience, consistent with an amygdaloid dependent modulation of emotional memory. It should be considered that the presentation of butyric acid or TMT was associated with discrete mesocortical CCK alterations in CD-1 mice owing to the perceived severity of stressor-like properties associated with the respective odor. Indeed, mild stressor exposure among infrahu- man subjects, ordinarily associated with alterations of DA and CCK sub-regions of the mesencephalon and mesocortex, induce gradient levels of dysphoria and anxiety while increased CCK availability in the basolateral amygdala is associated with increased vigilance and fear. In effect, sustained elevation of central CCK has been linked to the protracted impact of stressors on motivation and anxiety in clinical samples.

\section{ACKNOWLEDGMENTS}

This research was supported by grants from the Natural Sciences and Engineering Research Council of Canada, Canadian Institute of Health Research and the Gustavus and Louis Pfeiffer Research Foundation. G.D. held a scholarship from le Fonds de la Recherche en Santé du Québec (FRSQ).

\section{REFERENCES}

Adamec RE (2001): Does long term potentiation in periaqueductal gray (PAG) mediate lasting changes in rodent anxiety-like behavior (ALB) produced by predator stress?-Effects of low frequency stimulation (LFS) of PAG on place preference and changes in ALB produced by predator stress. Behav Brain Res 120:111-135

Berton F, Vogel E, Belzung C (1998): Modulation of mice anxiety in response to cat odor as a consequence of predators diet. Physiol Behav 65:247-254

Blanchard RJ, Blanchard CD, Rodgers RJ, Weiss SM (1990): The characterization and modelling of antipredator defensive behavior. Neurosci Biobehav Rev 14:463-472

Blanchard DC, Blanchard RJ (1988). Ethoexperimental approaches to the biology of emotion. In Rosenzweig MR, Porter LW (eds), Annual Review of Psychology 39. Palo Alto, CA, Annual Reviews Inc., pp 43-68

Blanchard DC, Blanchard RJ, Rodgers RJ (1990): Pharmacological and neural control of anti-predator defense in the rat. Aggressive Behavior 16:165-175

Blanchard RJ, Hebert MA, Ferrari P, Palanza P, Figueira R, Blanchard DC, Parmigiani S (1998): Defensive behaviors in wild and laboratory (Swiss) mice: the mouse defense test battery. Physiol Behav 65:201-209

Bradwejn J, Koszycki D, Meterissian G (1990): Cholecystokinin tetrapeptide induces panic attacks in patients with panic disorder. Canadian Journal of Psychiatry 35:83-85

Calvo-Torrent A, Brain PF, Martinez M (1999): Effect of predatory stress on sucrose intake and behavior on the plus-maze in male mice. Physiol Behav 67:189-196

Chomezinski P, Sacchi N (1987): Single-step method of RNA isolation by acid guanidinium thiocyanate-phenol-chloroform extraction. Annals Biochem 162:156-159

Cohen H, Kaplan Z, Kotler M (1998): Inhibition of anxiety in rats by antisense to cholecystokinin precursor protein. Biol Psychiatry 44:915-917

Crawley J, Goodwin FK (1980): Preliminary report of a simple animal behavior model for the anxiolytic effects of benzodiazepines. Pharmacol Biochem Behav 13:167-170 
Crump DR, Moors PJ (1985): Anal gland secretions from the stoat (mustela erminea) and the ferret (mustela putorius forma): some additional thietane components. J Chemic Ecolog 11:1037-1043

Davidson RJ, Irwin W (1999): The functional neuroanatomy of emotion and affective style. Trends Cogn Sci 3:11-21

Davis M (1992): The role of the amygdala in fear and anxiety. Ann Rev Neuroscience 15:353-375

Davis M, Shi C (1999): The extended amygdala: are the central nucleus of the amygdala and the bed nucleus of the stria terminalis differentially involved in fear versus anxiety? Ann NY Acad Sci 877:281-291

File SE, Gonzalez LE, Gallant R (1998): Role of the basolateral nucleus of the amygdala in the formation of a phobia. Neuropsychopharmacology 19:397-405

Furmark T, Fischer H, Wik G, Larsson M, Fredrikson M (1997): The amygdala and individual differences in human fear conditioning. Neuroreport 8:3957-3960

Garbe CM, Kemble ED, Rawleigh JM (1993): Novel odors evoke risk assessment and suppress appetitive behaviors in mice. Aggressive Behavior 19:447-454

Gewirtz JC, Falls WA, Davis M (1997): Normal conditioned inhibition and extinction of freezing and fear-potentiated startle following electrolytic lesions of medial prefrontal cortex in rats. Behav Neurosci 111:712-726

Gewirtz JC, McNish KA, Davis M (1998): Lesions of the bed nucleus of the stria terminalis block sensitization of the acoustic startle reflex produced by repeated stress but not fear-potentiated startle. Prog Neuropsychopharmacol Biol Psychiatry 22:625-648

Graeff FG, Silveira MCL, Nogueira RL, Audi E, Oliveira RMW (1993): Role of the amygdala and periaqueductal gray in anxiety and panic. Behav Brain Res 58:123-131

Granon S, Passetti F, Thomas KL, Dalley JW, Everitt BJ, Robbins TW (2000): Enhanced and impaired attentional performance after infusion of D1 dopaminergic receptor agents into rat prefrontal cortex. J Neurosci 20:1208-1215

Hamilton ME, Freeman AS (1995): Effects of administration of cholecystokinin into the VTA on DA overflow in nucleus accumbens and amygdala of freely moving rats. Brain Res 688:134-142

Hogg S, File SE (1994): Responders and nonresponders to cat odor do not differ in other tests of anxiety. Pharmacol Biochem Behav 49:219-222

Hooks MS, Kalivas PW (1995): The role of mesoaccumbenspallidal circuitry in novelty-induced behavioral activation. Neuroscience 64:587-597

Hotsenpiller G, Williams JL (1997): A synthetic predator odor (TMT) enhances conditioned analgesia and fear when paired with a benzodiazepine receptor inverse agonist (FG-7142). Psychobiology 25:83-88

Jinks AL, McGregor IS (1997): Modulation of anxiety-related behaviours following lesions of the prelimbic or infralimbic cortex in the rat. Brain Res 722:181-190

Kemble ED (1994). Novel odors increase defensiveness and inhibit attack behavior in mice. In Cooper SJ, Hendrie CA (eds), Ethology and Psychopharmacology. Chichester, John Wiley, pp 191-204

Kemble ED, Bolwahnn BL (1997): Immediate and long-term effects of novel odors on risk assessment in mice. Physiol Behav 61:543-549

Kilfoil T, Michel A, Montgomery D, Whiting RL (1989): Effects of anxiolytic and anxiogenic drugs on exploratory activity in a simple model of anxiety in mice. Neuropharmacology 28:901-905

Lanca AJ, De Cabo C, Arifuzzaman AI, Vaccarino FJ (1998): Cholecystokinergic innervation of nucleus accumbens subregions. Peptides 19:859-868

Legault M, Wise RA (2001): Novelty-evoked elevations of nucleus accumbens dopamine: dependence on impulse flow from the ventral subiculum and glutamatergic neurotransmission in the ventral tegmental area. Eur J Neurosci 13:819-828

Lofberg C, Agren H, Harro J, Oreland L (1998): Cholecystokinin in CSF from depressed patients: possible relations to severity of depression and suicidal behavior. Eur Neuropsychopharmacol 8:153-157

Lu XC, Slotnick BM, Silberberg AM (1993): Odor matching and odor memory in the rat. Physiol Behav 53:795-804

MacNeil G, Sela Y, McIntosh J, Zacharko RM (1997): Anxiogenic behavior in the light-dark test following intraventricular administration of cholecystokinin-8S, restraint stress, or uncontrollable footshock in the CD-1 mouse. Pharmacol Biochem Behav 58:737-746

McGregor IS, Dielenberg RA (1999): Differential anxiolytic efficacy of a benzodiazepine on first versus second exposure to a predatory odor in rats. Psychopharmacology (Berl) 147:174-181

Molewijk HE, van der Poel AM, Olivier B (1995): The ambivalent behavior "stretched approach posture" in the rat as a paradigm to characterize anxiolytic drugs. Psychopharmacology (Berl) 121:81-90

Morgan M, LeDoux JE (1995): Differential contribution of dorsal and ventral medial prefrontal cortex to the acquisition and extinction of conditioned fear. Behav Neurosci 109:681-688

Morrow BA, Redmond AJ, Roth RH, Elsworth JD (2000): The predator odor,TMT, displays a unique, stress-like pattern of dopaminergic and endocrinological activation in the rat. Brain Res 864:146-151

Paxinos G, Franklin KBJ (1997): The mouse brain in stereotaxic coordinants, San Diego, CA, Academic Press

Pavlasevic S, Bednar I, Qureshi GA, Sodersten P (1993): Brain cholecystokinin tetrapeptide levels are increased in a rat model of anxiety. Neuroreport 5:225-228

Post RM, Weiss SR, Li H, Smith MA, Zhang LX, Xing G, Osuch EA, McCann UD (1998): Neural plasticity and emotional memory. Dev Psychopathol 10:829-855

Rattray M, Singhvi S, Wu PY, Andrews N, File SE (1993): Benzodiazepines increase preprocholecystokinin messenger RNA levels in rat brain. Eur J Pharmacol 245:193-196

Rosenkranz JA, Grace AA (2001): Dopamine attenuates prefrontal cortical suppression of sensory inputs to the basolateral amygdala of rats. J Neurosci 21:4090-4103

Vernet-Maury E (1980). Trimethylthiazoline in fox feces: A natural alarming substance for the rat. In van der Starre $\mathrm{H}$ (ed), Olfaction and Taste (Vol. 7, p. 407). Washington, DC, IRL, p 407

Vernet-Maury E, Constant B, Chanel J (1992): Repellent 
effect of trimethyl-thiazoline in the wild rat Rattus norvegicus Berkenhout. In Doty RL, Muller-Schwarze D (eds), Chemical Signals in Vertebrates, Vol. 6. New York, Plenum, pp 305-310

Vos PE, Steinbusch HW, Ronken E, van Ree JM (1999): Short and long term plasticity after lesioning of the cell body or terminal field area of the dopaminergic mesocorticolimbic system in the rat. Brain Res 831: 237-247
Wallace KJ, Rosen JB (2000): Predator odor as an unconditioned fear stimulus in rats: elicitation of freezing by trimethylthiazoline, a component of fox feces. Behav Neurosci 114:912-922

Zibrowski EM, Hoh TE, Vanderwolf CH (1998): Fast wave activity in the rat rhinencephalon: elicitation by the odors of phytochemicals, organic solvents, and a rodent predator. Brain Res 800:207-215 